\title{
A BIOECONOMIC MODEL BY QUANTITATIVE BIOLOGY TO ESTIMATE SWINE PRODUCTION
}

\author{
Hui Yuan ${ }^{2}$, Surong Xiao ${ }^{1}$, Qiujuan Wang ${ }^{2}$, Keliang $\mathrm{Wu}^{2, *}$ \\ ${ }^{1}$ Shanghai Xiangxin Livestock, Ltd. 201302 \\ ${ }^{2}$ College of Animal Science and Technology, China Agricultural University, Beijing, 100094 \\ *Corresponding author, Tel: +86-10-62733445, Email: liangkwu@cau.edu.cn
}

Abstract: A bioeconomic computer model was constructed to simulate biological and economic inputs and outputs for life cycle swine production. Parameters and relationships used in model were developed and verified by comparison with experimental results in the literature. The bioeconomic model was constructed by several modules such as growth and development, pregnancy, lactation, and replacement gilt etc. The result is: (1) the bioeconomic computer model was efficient way to describe pig production system and research factors' effect and their interactions. (2) Traits in the model were: oestrus traits; mature weight and feed requirements of sows; longevity of sows; litter size; growth rate and daily feed intake of young pigs and fatteners; mortality rate of pigs. (3) Sow longevity is 2.12 years and yearly culling rate is $47.20 \%$. Yearly farrowing sow is 2.08 and total numbers of farrowings per gilt is 4.62. (4) Average litter size total born is 11.23 , litter size born alive is 10.40 , litter size weaned is 8.80 .

Keywords: Quantitative Genetics, Economics, Computer Simulation, Swine, System Analysis

\section{INTRODUCTION}

A deterministic computer model is a theory and research methodology (Emmans and Fisher, 1986) in many sense, which integrated multidiscipline, such as nutrition, genetics, physiology, meats and economics to describe a production system of livestock. 
The methodology of simulation pig production by computer model was named quantitative biology of the pig (Kyriazakis, 1999). That is pig production biological processes can be described by model methodology.

Model methods were applied in simulation livestock production system. For example, De Hatog et al. (1995) reviewed the pig growth models. De Vries (1989) estimated economic values of traits in pig breeding by computer simulation model. The swine simulation model were reported by other researchers (Emmans, 1995; Poma et al., 1991; Schinckel et al., 1996; Whittemore, 1995).

The objective of present study is to construct a pig production model that are in agreement with Chinese farm by means of quantitative biology of pig. Dealing with the biological processes which underlie pig production, a computer simulation model was built to describe the production procedures of mating, pregnancy, farrowing, lactation and growth production.

\section{MODEL DESCRIPTION}

\subsection{Condition and strategy}

According to current swine production process of Chinese farm, the methodology of swine quantitative biology is applied to build different stage in swine production system that is mating, pregnancy, farrowing, lactation, growth and development. The different biological procedures were described by mathematical formula and computer program written in FORTRAN-90.

When a computer model, which was in agreement with current situation and production level of Chinese swine production, was built, some features should be taken into account:

First, the model is on the basis of the production performance of the world's main breed (such as Large White and Landrace).

Second, the model can reflect production state of special genetic level exactly.

Third, for the sake of the maximum genetic potential of swine and Chinese actual situation in swine industry sufficiently, the ad lib feeding system is implemented at the stage of growth, and controlled feeding system is executed at the stage of replacement gilts, sow.

Final, the value of the model's biological parameters is determined by some composite factors including the production consequences of Chinese swine farm and the results of experiment research in the literature. 


\subsection{Modules construction}

The different modules, which include mating, pregnancy, farrowing, lactation, growth and development, were constructed according to swine life cycle of production systems.

\subsubsection{Growth}

The growth is one of the most important stages of swine, directly relating with the level and the production benefit of pig production.

The growth module is based on the growth and development of swine's body components, namely this module is respectively constructed according to the growth and development scale of the four body components (water, protein, lipid and ash). The equations (WU Keliang, 2004) are used to predict the four body compartment and live body weight.

Liveweight (LWT), LWT $=217.498 e^{-4.4134 e^{-0.0113 x d a y}}$

Body protein retention $(\operatorname{Pr}), \operatorname{Pr}=0.304$ EBWT0.8288

Body lipid retention (Lipid), Lipid $=0.00647$ EBWT1.8422

Body water gain $(\mathrm{Wa}), \mathrm{Wa}=1.984 \mathrm{EBWT} 0.6921$

Body ash reserves (Ash), Ash $=0.0238+0.0651$ EBWT

The live weight (LWT) of growing swine is represented by Equation Gompertz, xday represents swine's growth age in days. EBWT is the empty body weight which is calculated from two approaches as follows:

The EBWT takes up 95\% of the live weight, i.e. EBWT $=0.95 \mathrm{LWT}$.

The EBWT is the algebraic sum of the four body components as described in the following equation: $\mathrm{EBWT}=\mathrm{Pr}+\mathrm{Lipid}+\mathrm{Wa}+$ Ash.

At the growth stage, growing pigs are fed ad libitum. And the requirement of growth is determined by deposition rate of body protein and lipid, which is calculated from the following equation:

$$
\mathrm{MEI}=\mathrm{MEm}+\mathrm{bp} \bullet \Delta \mathrm{P}+\mathrm{bF} \bullet \Delta \mathrm{F}
$$

Where MEI is daily metabolizable energy intake (Mcal/d); MEm is daily maintenance requirement $(\mathrm{Mcal} / \mathrm{d})$; bp and bF is energy costs of protein and lipid deposition (Mcal/d), respectively.

The energy value of lipid and protein are respectively $9.5 \mathrm{Mcal} / \mathrm{kg}$ and $5.7 \mathrm{Mcal} / \mathrm{kg}$ (den Hartog and vander Peet-Schwering, 1995). The feed conversion rate from metabolizable energy to lipid and protein are respectively 0.84 and 0.54 , namely the energy costs of protein and lipid deposition per kilogram are $10.56 \mathrm{Mcal}$ and $12.84 \mathrm{Mcal}$, respectively.

Consequently, the value of $\mathrm{bp}$ and $\mathrm{bF}$ determined by that research are respectively $10.56 \mathrm{Mcal} \mathrm{ME} / \mathrm{kg}$ and $12.84 \mathrm{Mcal} \mathrm{ME} / \mathrm{kg}$. 
The maintenance requirement can be concluded from the following equation of maintenance requirement model presented by Tess (1983):

$$
M E_{M}=0.126 \text { Mcal } \bullet L_{B M}^{0.83}
$$

Where $\mathrm{MEm}=$ The maintenance requirement of metabolizable energy, $\mathrm{LBM}=$ lean body mass.

\subsubsection{Replacement gilt}

The performance measurement for the growing pigs is terminated until their weight reach 90 kilogram. And then, after culling, the eligible gilts enter into replacement gilts group. The replacement gilts are generally restrictedly fed, which feed supply is $2.3 \mathrm{~kg} / \mathrm{d}$, and the rate of body deposition of body protein and lipid is $1: 1$ and the conversion ratio from feed ME to body components are 0.54 and 0.84 respectively.

The replacement gilts' breeding age in days is determined by two components: age at puberty and estrus period. The initial value of mating day in the model is the second estrus.

\subsubsection{Gestation}

The growth and development of fetus is key important for swine production. But there are not so many research reports on the growth and development of fetus. The fetus weight gain are more slowly at early stage of pregnancy (0-80 day), but more quickly at late stage of pregnancy (80-115 day). It is said that approximately $60 \%$ of weight gain of fetus is in the late stage of pregnancy.

Gestation simulation in the model is based on the following equation (Noblet, 1990).

$$
\mathrm{fw}=\exp \left(9.095-17.69 * \exp \left(-0.0305^{*} \text { gday }\right)+0.0878 * \text { tb }\right)
$$

Where $\mathrm{fw}=$ the weight of fetus development; gday = pregnancy time (day); tb = litter size.

In this model, the growth and development of fetus in primiparous or multiparous sow is the same. The weight of embryonic membrance and amnionic fluid increase constantly with fetus's growth and development stages. It is studied that the weight of embryonic membrance and amnionic fluid is about $10 \mathrm{~kg}$ when the sow is delivering (Tess, 1983; Noblet, 1990).

Feed intake and feeding management of pregnant sow is adopt control feeding, relating with Chinese farm. The detail feeding schemes are shown as follows: $2.3 \mathrm{~kg}$ feed was available in early stage of pregnancy (0-84 day), $3.4 \mathrm{~kg}$ in the late phase of pregnancy (85-114 day), the energy (Mcal $/ \mathrm{kg}$ ) of feed is 2.65 megacalorie or 11.09 megajoule $(\mathrm{MJ} / \mathrm{kg})$, and the contents of protein is $12.0 \%$. 


\subsubsection{Lactation}

As known, more nutrient substance is essential for the lactating sow. King (1994) applied isotope dilution method to study the milking production of sows. The maximum daily milk potential of sows was likely to overrun $10 \mathrm{~kg}$ and the nutrient substance passing udder via blood was almost $7 \mathrm{~kg}$. The simulation of milk yield in this model adopt equation of Whittemore and Morgan (1990):

$$
\text { my }=\mathrm{a} * \exp (-0.025 * \text { lday }) * \exp (-\exp (0.5-0.1 * \text { lday }))
$$

Where my $=$ milking yield; $\mathrm{a}=\mathrm{a}$ variable parameter which is from 18 to 30 and its value is determined by sow's genetic background; In the model, the value of a is 24 ; lday = lactating time in days.

The milk yield is affected by parity number, litter size and stage of lactation, especially parities between number one and two. The milking production of primiparous sow is $80 \%$ of production of parous sow.

The nutritional requirement of lactating sow is divided into the lactating requirement and the maintenance requirement of sow.

$$
M E_{I}=M E_{M}+b_{M K} * \Delta M K
$$

Where $\mathrm{MEI}=$ intake of metabolizable energy of sow; $\mathrm{MEm}=$ metabolizable energy for maintenance requirement; $b M K=$ the ratio of feed conversion to milk; $\square \mathrm{MK}=$ variation of milk yield.

\subsubsection{Levels of genetic trait and parameters of swine production}

The confirmation of pig production parameters and performance is difficult, because of too many links and complicated factors. The performance of swine herd is related not only with genetic structure of swine, but also with other factors, for instance, nutrition environmental factors and management pattern and decision.

The fertility traits and culling rates listed in table 1 . The confirmation of production parameters in model is based on the followings: (1) the production performance form the JiangXi breeding swine farm, YunNan breeding swine farm and ShunXinLong Breeding Company in Beijing. (2) the surveyed data from other areas in China, for example, the price of semen or insemination. (3) the reported results in the literatures.

Table 1. Fertility traits and culling rates of sows per cycle number

\begin{tabular}{lcccccccccc}
\hline & \multicolumn{10}{c}{ Parity number } \\
\cline { 2 - 11 } & 1 & 2 & 3 & 4 & 5 & 6 & 7 & 8 & 9 & 10 \\
\hline IWO (d) & - & 12 & 9 & 8 & 8 & 7 & 7 & 7 & 7 & 7 \\
Marginal Culling rate (\%) & - & 14.7 & 16.1 & 17.5 & 18.9 & 20.3 & 22.4 & 24.5 & 26.6 & 30.1 \\
Litter size born alive & 9.4 & 10.1 & 10.6 & 10.9 & 11.0 & 10.9 & 10.8 & 10.7 & 10.6 & 10.5 \\
\hline
\end{tabular}

* IWO is interval wean-oestrus (days) 


\section{RESULTS}

\subsection{Results for growth performance}

The simulation performance of growth and development is listed in table 2. As shown in table 2, average weight of newborn piglets is $1.25 \mathrm{~kg}$, the weight of weaned piglet at 28 days is $7.40 \mathrm{~kg}$. the body weight of feeder pig at 55 days is to reach $25 \mathrm{~kg}$. It takes 143.6 days for pigs to reach $90 \mathrm{~kg}$ or 154.9 days to reach $100 \mathrm{~kg}$. The average daily growth (ADG) during the whole process reaching $90 \mathrm{~kg}$ and $100 \mathrm{~kg}$ is respectively $626.74 \mathrm{~g}$ and $645.58 \mathrm{~g}$.

Table 2. Results for production performance in growth stage

\begin{tabular}{lcccc}
\hline Ages in days & LWT $(\mathrm{kg})$ & LBM $(\mathrm{kg})$ & Protein $(\mathrm{kg})$ & Lipid $(\mathrm{kg})$ \\
\hline 0 & 1.25 & 1.2 & 0.1595 & 0.0145 \\
wean $(28 \mathrm{~d})$ & 7.40 & 6.1058 & 1.0175 & 1.0945 \\
$55 \mathrm{~d}$ & 25.00 & 12.01 & 2.1725 & 2.6133 \\
$143.6 \mathrm{~d}$ & 90.00 & 60.86 & 12.1405 & 23.46 \\
$154.9 \mathrm{~d}$ & 100.00 & 66.28 & 13.3676 & 28.73 \\
\hline
\end{tabular}

\subsection{Sow's reproduction performance}

Simulated performance of the sow herd is listed in table 3. the farrowing per sow yearly is 2.08 , the total number of born on average is 11.23 , and litter size weaned is 8.82 . The longevity of sow in breeding herd is 2.12 years, the total number of farrowings for sows was 4.62, the culling rate of sow per year is $47.20 \%$. The outputs of model about sows are in agreement with actual production situation in China.

Table 3. Simulated average performance of sows

\begin{tabular}{lc}
\hline Trait & Average value \\
\hline Average longevity of sow (year) & 2.12 \\
Cullings Sow per year $(\%)$ & 47.20 \\
Total born & 11.23 \\
Number born alive & 10.40 \\
Litter size weaned & 8.82 \\
Litter per sow per year & 2.08 \\
Total no. of farrowings for gilts & 4.62 \\
Mortality in suckling (\%) & 15.23 \\
\hline
\end{tabular}


Table 4. Simulated distribution of farrowings

\begin{tabular}{ccccccccccc}
\hline \multirow{2}{*}{\begin{tabular}{c} 
Distribution \\
\cline { 2 - 10 }$(\%)$
\end{tabular}} & 1 & 2 & 3 & 4 & 5 & 6 & 7 & 8 & 9 & 10 \\
& 20.00 & 17.27 & 14.55 & 12.27 & 10.00 & 8.18 & 6.36 & 5.00 & 3.64 & 2.73 \\
\hline
\end{tabular}

The simulated distribution of life cycle number is in table 4. The reproduction performance with sow parity is to reach a peak among parity $3-5$, so the reasonable distribution of the parity is the key importance for breeding herd.

\subsection{The growth and development of fetus}

The effect of stage of pregnancy on weight of fetus is shown in figure 1 . as shown in figure 1 , the weight gain of fetus is slowly in early stage of pregnancy (0-84d), but almost $2 / 3$ weight gain in late $30 \mathrm{~d}$ of pregnancy.

\subsection{Milk yield}

The milk yield of lactating sow is shown in figure 2. the peak of milk yield is approximately $12 \mathrm{~kg}$ at 17 days in lactation. Lactating sows seldom gain weight during lactation and generally lose weight. Sow body weight and chemical component changes during parity 1 and 5 listed in table 5. The body weight and content of body lipid for primiparous sow last permanently, but lose in some scale for sows.

Table 5. Sow bossdy weight and chemical component changes during parity 1 and 5

\begin{tabular}{llllllll}
\hline \multirow{2}{*}{ Days in lactation } & \multicolumn{3}{c}{ Parity 1 } & & \multicolumn{3}{c}{ Parity 5 } \\
\cline { 2 - 4 } \cline { 7 - 8 } & lipid & LBM & LWT & & lipid & LBM & LWT \\
\hline 1 & 33.68 & 118.98 & 160.70 & & 39.80 & 144.97 & 194.51 \\
10 & 34.13 & 120.94 & 163.24 & & 39.69 & 144.49 & 193.88 \\
20 & 33.98 & 120.29 & 162.39 & & 39.27 & 142.73 & 191.59 \\
28 & 33.86 & 119.79 & 161.75 & & 38.94 & 141.36 & 189.79 \\
\hline
\end{tabular}

\section{DISCUSSION}

The model used required a lot of information. The equations in model were not same according to researched works. However, the model can be evaluated in several ways to judge its suitability in fulfilling its designed purpose. First, the model was constructed in terms of biological process of performance at different stages in production system, so the detailed description of individual module of the model provides a verification of the 
model. Second, model output or the output of subunits of the model can be validated directly, by comparing simulated results with experimental results not used to construct the model.

The model of swine production is foundation works. The further research, for example, the design of optimum breeding programs, can be fulfilled.

\section{REFERENCES}

Amer, P. R., G. C. Fox and C. Smith 1994 Economic weights from profit equations: appraising their accuracy in the long run. Anim. Prod. 58:11-18.

Bourdon, B. M. 1998 Shortcoming of current genetic evaluation systems. J. Anim. Sci. 76:2308-2323.

Cameron, N. D. 1997 Selection indices and prediction of genetic merit in animal breeding. CAB INTERNATIONAL Wallingford, UK.

Chen, Y. C. 1998 Pig industry in China. Proc. of intern. conf. of pig production. Beijing 1-5.

Chen, R. S. 1996 Pig production in China. In: Pig Production edited by M. R. Taverner and A. C. Dunkin. Elsevier Science Publishers.

Cleveland, E. R., P. J. Cunningham and E. R. Peo, Jr. 1982 Selection for lean growth in swine. J. Anim. Sci. 54(4):719-727.

Clutter, A. C. and E. W. Brascamp 1998 Genetcs of performance traits. In "The genetics of the pig” edited by M. F. Rothschild and A. Ruvinsky. CAB INTERNATIONAL.

De Hartog, L. A. and C. M. C. van der Peet-Schwering 1995 The use of growth models for piga in practice. Pig News and Information. 16(2):51N-53N.

De Vries, A. G. 1989 A model to estimate economic values of traits in pig breeding. Livest. Prod. Sci. 21:49-66.

De Vries, A. G. 1989 A method to incorporate competitive position in the breeding goal. Anim. Prod. 48:221-227.

Emmans, G. C. 1995 Ways of describing pig growth and food intake using equations. Pig News and Information. 16(4):113N-116N.

Emmans, G. C. and I. Kyriazakis 1999 Growth and body composition. In: Kyriazakis, I. (eds). A Quantitative Biology of the Pig. CAB Publishing. 181-197.

Fredeen, H. T. 1980 Pig breeding: current programs vs. Future production requirements. Can. J. Anim. Sci. 60: 241-251.

Gibson, J. P. and J. W. Wilton 1998 Defining multiple-trait objectives for sustainable genetic improvement. J. Anim. Sci. 76:2303-2307.

Harris, D. L. 1998 Livestock improvement: Art, Science, or Industry? J. Anim. Sci. 76:22942302.

Herrero, M. R. H. Fawcett and J. B. Dent 1999 Bio-economic evaluation of farm management scenarios using integrated simulation and multiple-criteria models. Agricultural Systems 62:169-188.

King, R. H., J. LeDividich and F. R. Dunshea 1999 Lactation and neonatal growth. In: Kyriazakis, I. (eds). A Quantitative Biology of the Pig. CAB Publishing. 155-180.

Kyriazakis, I. 1999. A Quantitative Biology of the Pig. CAB Publishing.

Mclaren, D. G., D. S. Buchanan and J. E. Williams 1987 Economic evaluation of alternative cross-breeding systems involving four breeds of swine. I. The simulation model. J. Anim. Sci. 65:910-918. 
Mclaren, D. G., D. S. Buchanan and J. E. Williams 1987 Economic evaluation of alternative crossbreeding systems involving four breeds of swine. II. System Efficiency. J. Anim. Sci. 65:919-928.

Pomar, C., D. L. Harris and F. Minvielle 1991 Computer simulation model of swine production systems: I. Modeling the growth of young pigs. J. Anim. Sci. 69:1468-1488.

Pomar, C., D. L. Harris and F. Minvielle 1991 Computer simulation model of swine production systems: II. Modeling body composition and weight of female pigs, fetal development, milk production, and growth of suckling pigs. J. Anim. Sci. 69:1489-1502.

Schinckel, A. P. and C. F. M. de Lange 1996 Characterization of growth parameters needed as inputs for pig growth models. J. Anim. Sci. 74:2021-2036.

Shields, R. G., Jr., D. C. Mahan and F. M. Byers 1983 Efficiacy of deuterium oxide to estimate body composition of growing swine. J. Anim. Sci. 57(1):66-73.

Smith, C., D. E. Dickerson, M. W. Tess and G. L. Bennett 1983 Expected relative responses to selection for alternative measures of life cycle economic efficiency of pork productiion. J. Anim. Sci. 56(6):1306-1314.

Taverner, M. R. and A. C. Dunkin. 1996 Pig production World Animal Science, C10. Elsevier Science Publishers.

Tess, M. W., G. L. Bennett and G. E. Dickersion 1983 Simulation of genetic changes in life cycle efficiency of pork production. I. A bio-economic model. J. anim. Sci. 56(2):336-353.

Tess, M. W., G. L. Bennett and G. E. Dickersion 1983 Simulation of genetic changes in life cycle efficiency of pork production. II. Effects of components on efficiency. J. anim. Sci. 56(2): 54-379.

Van der Peet-schwering, C. M. C., L. A. den Hartog and H. J. P. M. Vos 1999 Application of growth models for pigs in practice - Review. Asian-Aus. J. Anim. Sci. 12(2):282-286.

Weatherup, R. N., V. E. Beattie, B. W. Moss, D. J. Kilpatrick and N. Walker 1998 The effect of increasing slaughter weight on the production performance and meat quality of finishing pigs. Anim. Sci. 67:591-600.

Webb, A.J. 1996 Future challenges in pig genetics. Pig news and Information. 17(1):11-16.

Webb, A. J. 1986 Selection regime by production system interaction in pig improvement: A review of possible csuses and solutions. Livest. Prod. Sci. 14:41-54.

Whittemore, C. T., J. C. Kerr and N. D. Cameron 1995 An approach to prediction of feed intake in growing pigs using simple body measurements. Agri. Syst. 47: 235-244.

Whittemore, C. T. 1986 An approach to pig growth modeling. J. Anim. Sci. 63:615-621.

Whittemore, C. T., J .B. Tullis and G. C. Emmans 1988 Protein growth in pigs. Anim. Prod. 46: 437- 445.

Wu, Ch. X. 1998 Pig breeding in China. Proc. of intern. conf. of pig production. Beijing 6-8

Zhang, H. F., Zhang Z. Y. 1998 Today and yesterday of swine industry in China \& sustainable development in strategy. Proc. of intern. conf. of pig production. Beijing 703-705. 